\title{
Getting Foxy: Invoking Different Magesteria in the Scholarship of Teaching and Learning
}

\section{ABSTRACT}

Higher education has seen an increase in the number of faculty conducting scholarship of teaching and learning (SoTL). Unfortunately, the momentum of this movement is somewhat thwarted by debates over which methodology should take center stage. The discussion often pitches quantitative experimentation against qualitative approaches and mistakenly represents each method as characterizing the domains of social science and the humanities, respectively. Does one methodology reign supreme? In this article I argue that not only are the humanities and the social sciences misrepresented, but both methodologies have a lot to contribute to SoTL. The social sciences and humanities, in fact, share many methodologies although they are each sometimes characterized as separate magisteria. I enumerate specific reasons why stereotypical social science methodology and that of the humanities are both useful for SoTL. I draw special attention to the time and place for statistical analyses and advocate for a 'fox-like' strategy to SoTL, one that involves utilizing mixed-methods research designs, and the collection of both quantitative and qualitative evidence.

\section{KEYWORDS}

social sciences, humanities, research methods, pedagogy, SoTL

Should faculty from the humanities know how to use social science methodologies to conduct scholarship of teaching and learning (SoTL)? Although this question is often heard at faculty development conferences and workshops, it mistakenly stereotypes each discipline assuming all humanists use a qualitative approach and all social scientists use the quantitative approaches. Some SoTL faculty from the humanities and the arts consequently feel pressured to know how to design experiments and conduct statistical analyses. Pressure aside, "We do not care about $p$ values or statistical significance. If you do, you calculate it!" is what some faculty retort. I argue that not only are methodologies varied within both the humanities and the social sciences, both qualitative and quantitative approaches have a lot to contribute to SoTL.

SoTL is getting popular. There is a brand new journal for it coming out almost every year. Teaching and Learning Inquiry in 2013, SoTL in Psychology in 2014, join a host of other journals publishing research on teaching and learning (e.g., Teaching of Psychology, International Journal on the Scholarship of Teaching and Learning). Pat Hutchings, Mary 
Taylor Huber, and Anthony Ciccone of the Carnegie Foundation for the Advancement of Teaching recently showcased how SoTL has an impact on and has been integrated into higher education (Scholarship of Teaching and Learning Reconsidered, 2011).

SoTL entails methodologically rigorous scholarly work conducted to enhance teaching and advance learning. It is commonly described as intentional, systematic reflections on teaching and learning resulting in peer-reviewed products made public (Gurung \& Schwartz, 2012; Potter \& Kustra, 2011). Boyer popularized the term "scholarship of teaching" in his Scholarship Reconsidered, although caring teachers have practiced the kind of work it refers to for many years. Even though the extent to which SoTL is counted as scholarship towards merit, tenure, and promotion varies across the United States, more departments at more universities are including SoTL in faculty reviews. But is there a best way to do it? Does one discipline hold the key to the kingdom?

Some of the rhetoric in SoTL presentations and publications does seem to imply that quantitative methodologies and the scientific method are the key ways to do SoTL (Maurer, 2011). For example, results from a survey of editors of SoTL journals suggested manuscripts did not get published because, among other reasons, they featured inadequate data analysis' (Jarvis \& Creasey, 2009). Alluding to pressures felt by some SoTL researchers to use the scientific method, Grauerholz and Main (2013) discuss how the scientific method cannot be fully used. Poole (2013) takes this discussion a step further to unpack what is (and what should be) meant by 'research' in the first place. Whereas benchmarks for SoTL in psychology are understandably explicitly empirically based (Wilson-Doenges \& Gurung, 2013) a universal set of good practices for SoTL need not be and are not at all (Felten, 2013).

In many ways these expositions resemble the age-old battle between the sciences and the humanities in general. Stephen Jay Gould famously argued that the two were 'separate magisteria' each with their own domains, not overlapping in any way. One, social science, answered the how questions, the other, humanities, answered the 'why' questions. More recently, White (2013) flies the flag for the humanities calling science a 'delusion' and for a return to Romanticism. Whereas pitching the humanities against the social sciences makes for great intellectual debate, it is a sideshow and a distraction risking the derailment of advancing SoTL. One can spend a lot of time comparing various definitions of SoTL (Potter \& Kustra, 2011 for a review) or one can just do it-focus on formulating questions about teaching and learning, educating oneself on what has been done on the topic, and the best methodologies to answer the question in a discipline-agnostic fashion.

Most importantly, pitching the social sciences against the humanities mistakenly stereotypes the practitioners of each discipline. This apparent divide probably arose from the fact that there are methods and paradigms that the social sciences and humanities do not share. For example, the use of textual analysis or close reading is more common in the humanities, and the tendency toward more positivist beliefs in "truth" in more common in the social sciences. This notwithstanding, although the majority of social scientists do use quantitative methods, run statistical analyses, and examine probability values, it is inaccurate to assume that all social scientists use quantitative methods. Similarly, although many humanists take a constructivist approach and utilize qualitative methodologies never needing a statistical program or a calculator to analyze their data or evidence of student learning, it is inaccurate to assume all humanists only use qualitative approaches. Increas- 
ingly, social scientists are using qualitative methods and approaches such as grounded theory and humanists are using quantitative methods such as content analysis.

The reality is that there are many ways to gather knowledge, and methods of inquiry vary across disciplines (Creswell, 2014; Rubin \& Rubin, 2012). Disciplines such as English and History primarily take the hermeneutical approach, in which interpretation is important and textual meaning is constructed through a blend of understanding and explanation (Donald, 2002). In the social sciences, the scientific method and quantitative methods dominate although other methodologies are also used. Scientific approaches favor empirical demonstrations, the use of objective methods, and the replication of findings. The reality is that both these approaches have their uses and it behooves SoTL researchers to have at least a sense of both of them.

Being skilled at one approach is commendable but may be limiting in that you may only ask the questions that your approach can study. Gould nicely draws our attention to an ancient Greek proverb that provides an apt warning: Multa novit vulpes, verum echinus unum magnum-The fox devises many strategies: the hedgehog knows one great and effective strategy (Archilochus in Erasmus, 1500, in Gould, 2003). If when trapped the hedgehogs' one strategy, rolling into a ball, does not work, it is all over. The fox with many alternatives at her disposal fares better. Likewise, whether social scientist or humanist, the more strategies one has to find meaning, describe and explore learning, and examine the evidence, the better. SoTL practitioners have enough challenges and threats ranging from fighting for recognition of the scholarship as 'good enough' to finding time to do it and making it count. Why add the age-old battle between science and the humanities? Let's be like the fox instead.

Perhaps the real question is whether all SoTL researchers should learn quantitative methodologies? To a large extent the answer depends on the question. Different questions call for different methods to get the best answer. There are three main reasons why quantitative methodology is useful and it should be noted that the methods and analyses mentioned are by no means restricted to the sciences. Quantitative methods, exemplified by the scientific method, involve a procedure or plan of action whereby one first observes a phenomenon, forms a theory that potentially explains the phenomenon, generates testable guesses or hypotheses about the phenomenon based on the theory, designs a research study and collects evidence to test the hypothesis, and finally evaluates the hypothesis. This approach is referred to as a quantitative approach. Quantitative approaches are often pitted against qualitative approaches whereby one studies the phenomenon in depth, taking detailed notes on it and gathering as much information about it from the sample of interest, and then looking for themes in what is gathered (Creswell \& Piano Clark, 2012).

So what can the social sciences contribute? First, social science research nicely alerts us to the fact that the changes we may see in our students' learning may be due to a whole host of factors, one of which may indeed be what we do as instructors or what the students have done (perhaps because of our instruction), but may also be likely due to other naturally occurring factors. People change over time (i.e., maturation). Factors outside our awareness influence results (i.e., history). It is possible that changes we see in our student's learning are due to these natural changes or factors external to our instructional interventions. Social science methodology alerts us to these two confounds, to many others, and most importantly, to ways to avoid them. 
Second, quantitative social science methodology involves significance testing. It is not enough to just observe change in student learning, but it is important to ask if that change was statistically significant. Assessing change is one type of pedagogical endeavor that necessitates the quantitative method regardless of discipline. If you want to know if students improved after a change you made (e.g., a new assignment, an innovative presentation, group work, flipping your class), you should know if that change would have happened by chance or if any other factors could account for it. This requires quantification of the evidence (e.g., themes brought up in a close reading, concepts used in essays, levels of meaning). When social scientists ask if the change is statistically significant, they really want to ensure that the change is due to what was done and not just due to chance. Stated in this way, it seems hard to not care about statistical significance. If you have worked hard to change your instruction and improve student learning, it is important to know whether that change would have happened by chance and without your intervention in the first place. Before one spends more time and energy on changing instruction or even trying to get others to also change instruction based on the changes you have seen, you should be sure your changes are not random and would not have occurred naturally (e.g., a practice effect). Statistical testing does this for you.

Statistical significance need not be the ultimate and only criterion for quality SoTL but it is certainly something to be considered for appropriate and relevant research designs and questions. Furthermore, statistical significance should not be confused with or taken to be synonymous with 'significant' as used in everyday life (i.e., to mean important). Misinterpreting this term can easily make disciplines that do not use statistical testing feel unwelcome. There are many ways to conduct scholarship, make meaning, and demonstrate knowledge especially in the humanities and fine arts, which do not require statistical testing (Chick, 2013).

Finally, having even a basic working knowledge of social science methodology helps us better digest the published literature in SoTL that may use this methodology. An expert SoTL practitioner should read the literature from a diverse array of disciplines. Being familiar with the approaches of the different disciplines will both ensure critical thinking about the results of SoTL from the different disciplines but may also provide one with novel ways to approach one's own SoTL. There are times when qualitative approaches provide key insights, and other times when quantitative approaches may be more suitable to the pedagogical question raised.

Starting with disciplinary methodologies and approaches you are comfortable with (and know how to use) makes great sense, but why stop there? If your focus is learning in general, it makes better sense to develop your question and then pick the best methodology for the question regardless of what discipline it comes from. This may involve collaboration and reading up on how other disciplines conduct SoTL (Chick, Haynie, \& Gurung, 2012; Gurung, Chick, \& Haynie, 2009). The question: Are my students learning my disciplinary content is easily and better subsumed in the more general question: Are my students learning?

To best unpack the complex enigma that is learning, we need to use the best tools possible. This involves stepping outside our disciplinary comfort zones, crossing magesteria, to inform our SoTL. To foster a deeper understanding of the interconnections underlying learning, economists should know where historical data come from, sociologists should 
know how to think like economists, political scientists would benefit from understanding how models are tested in psychology, historians should learn how political processes are studied, psychologists should understand sociological theories, and so forth (Gelman \& Cortina, 2009). Having a sense of the different models and different ways of thinking in different disciplines informs one's own scholarship. The question is not: "What discipline is doing the best SoTL?" or "Do I have to learn how to use methods I am not familiar with?" The question should be: What is the best way to answer my pedagogical research question? Not surprisingly, social scientists' questions are more amenable to quantitative measures and humanist's questions are more amenable to qualitative approaches. Humanists may not care about the questions that require the scientific method just as social scientists may not care about quests exclusively for meaning.

The humanities have many sophisticated ways of answering questions. There is certainly no need to shoehorn quantitative methodologies in where they are not apt. Often purely quantitative measures (e.g., responses to a priori created questions completed using a Likert-type scale) miss out on capturing the richness of experiences, thought processes, and conceptual paths followed by individuals. For example, few, if any quantitative measures can get at what students see in a text, in the same way that use of close reading can (Brummett, 2010). Qualitative evidence makes learning processes and pitfalls transparent in ways quantitative evidence cannot.

Does a qualitative researcher need to know about quantitative research? My answer is that it can only help in general, but especially if examining changes in learning. By the same token, a quantitative scientist should know about qualitative methodologies as well. In many ways, this is the 'greatest enterprise of the mind, ... the attempted linkage of the sciences and the humanities' (Wilson, 1998, p. 8). When you want to describe, explore, and examine something as complex as learning, nothing short of mixed-methods researchseamlessly blending quantitative and quantitative approaches and methodologies - will do the trick. Let's be like the fox.

Regan A. R. Gurung is Ben J. \& Joyce Rosenberg Professor of Human Development \& Psychology at the University of Wisconsin-Green Bay (USA).

\section{ACKNOWLEDGEMENTS}

The author acknowledges David Voelker and Joan Mittendorf for providing the impetus for the writing of this essay and for their insights. A special thanks to Cyndi Kernahan, Tony Ciccone, members of the University of Wisconsin System Office of Professional Development Council, and editors Gary Poole and Nancy Chick who provided valuable suggestions to strengthen this piece.

\section{REFERENCES}

Beummwtt, B. (2010). Techniques of close reading. Los Angeles, CA: Sage.

Chick, N. (2013). Difference, privilege, and power in the scholarship of teaching and learning: The value of humanities SoTL. In K. McKinney (Ed.) The scholarship of teaching and learning in and across the disciplines (pp. 152-168). Bloomington, IN: Indiana University Press.

Chick, N., Haynie, A., \& Gurung, R. A. R. (Eds.) (2012). Exploring more signature pedagogies. Sterling, VA: Stylus. 
Creswell, J.W. (2014). Research design: Qualitative, quantitative, and mixed methods approaches. Los Angeles, CA: Sage.

Creswell, J. W., \& Piano Clark, V. L. (2012). Designing and conducting mixed methods research. Thousand Oaks, CA: Sage.

Donald, J. G. (2002). Learning to think: Disciplinary perspectives. San Francisco: Jossey-Bass.

Felten, P. (2013). Principles of good practice in SoTL. Teaching and Learning Inquiry, 1, 121-126.

Gelman, A., \& Cortina, J. (Eds.) (2009). A quantitative tour of the social sciences. New York: Cambridge University Press.

Gould, S. J. (2003). The hedgehog, the fox, and the magister's pox: Mending the gap between the sciences and the humanities. New York: Three Rivers Press.

Grauerholz, L. \& Main, E. (2013). Fallacies of SoTL: Rethinking how we conduct our research. In K. McKinney (Ed.) The scholarship of teaching and learning in and across the disciplines (pp. 152-168). Bloomington, IN: Indiana University Press.

Gurung, R. A. R., Chick, N., \& Haynie, A. (Eds.) (2009). Exploring signature pedagogies: Approaches to teaching disciplinary habits of mind. Sterling, VA: Stylus.

Gurung, R. A. R., \& Schwartz, B. (2009). Optimizing teaching and learning: Pedagogical Research in Practice. Wiley Blackwell Publishing. London.

Jarvis, P., \& Creasey, G. (October, 2009). Strengthening SoTL Research: The Voices of Editors. Presented at the International Society for the Scholarship of Teaching and Learning, Bloomington, IN.

Maurer, T. (2011). On publishing SoTL articles. International Journal for the Scholarship of Teaching and Learning, 5. Retrieved from http://academics.georgiasouthern.edu/ijsotl/

Poole, G. (2013). Square one: What is research? In K. McKinney (Ed.) The scholarship of teaching and learning in and across the disciplines (pp. 152-168). Bloomington, IN: Indiana University Press.

Potter, M. K., \& Kustra, E. (2011). The relationship between scholarly teaching and SoTL: Models, distinctions, and clarifications. International Journal for the Scholarship of Teaching and Learning, 5. Retrieved from www.georgiasouthern.edu/ijsotl

Rubin, H. J., \& Rubin, I. S. (2012). Qualitative interviewing: The art of hearing data (3 ed). Los Angeles, CA: Sage.

Schwartz, E., \& Gurung, R. A. R. (2012). Evidence-based teaching in higher education. Washington, DC: American Psychological Association.

Voelker, D., \& Gurung, R. A. R. (2013). The scholarship of teaching and learning (SoTL): A discussion. Retrieved from http://www.uwsa.edu/opid/

White, C. (2013). The science delusion: Asking the big questions in a culture of easy answers. New York: Melville House.

Wilson-Doenges, G., \& Gurung, R. A. R. (2013). Benchmarks for scholarly investigations of teaching and learning. Australian Journal of Psychology, 65(1), 63-70. doi:10.1111/ajpy.12011

Wilson, E. O. (1998). Consilience: The utility of knowledge. New York: Vintage Press. 